\title{
EFFECTS OF THERMAL POLLUTION ON THE SOFT-BOTTOMS SURROUNDING A POWER STATION IN THE CANARY ISLANDS (NE ATLANTIC OCEAN)
}

\author{
Rodrigo Riera*1, Jorge Núñez ${ }^{2}$ and Daniel Martín ${ }^{3}$ \\ ${ }^{1}$ CIMA SL, C/Arzobispo Elías Yanes, 44, 38206 La Laguna, Tenerife, Canary Islands, Spain. \\ *corresponding author: rodrigo@cimacanarias.com \\ ${ }^{2}$ Department of Animal Biology, Faculty of Biology, University of La Laguna, 38206 La Laguna, \\ Tenerife, Canary Islands, Spain. \\ ${ }^{2}$ Centre d'Estudis Avançats de Blanes (CEAB-CSIC), Carrer d'accés a la Cala Sant Francesc 14, 17300 \\ Blanes, Girona, Spain
}

\begin{abstract}
The spatial and temporal effects of hot seawater $\left(60-70^{\circ} \mathrm{C}\right)$ from a power station on nearby soft-bottom communities were analyzed in the protected area "Sebadales del sur de Tenerife" (SE coast of Tenerife, Canary Islands, NE Atlantic Ocean). Sediment samples were taken during summer 2003 and winter 2004 from 12 to $20 \mathrm{~m}$ depth. The highest macrofaunal abundance and species richness were found in the turbines. A particular community, characterized by the polychaetes Aponuphis bilineata and sabellids of the genus Chone and the amphipod Photis longicaudata, inhabited the surroundings of the power station turbines, which differed from the remaining studied stations. The continuous current from sea effluent was the main responsible of the macrofaunal community structure in nearby sediments since no measurable responses to thermal disturbance were detected.
\end{abstract}

Key words: Macrofauna, Polychaeta, Amphipoda, soft-bottoms, thermal pollution, Tenerife, Canary Islands. 


\section{INTRODUCTION}

In coastal zone settlements, the construction of power plants is needed for energetic requirements. This industry uses seawater as a coolant and have effects on coastal organisms and ecosystems through the mortality of organisms entrained in the seawater taken into the plants, as well as, by effects of discharge heated water into the sea [22]. In general, water discharge from power-generating plants is roughly $10^{\circ} \mathrm{C}$ warmer than receiving waters.

The effects of thermal pollution on macrofaunal communities have been considered in several previous studies and results are different depending on the studied work. The effects of the warmer water within the limited spaces where heating was detectable were both negative and positive. For instance, [17] observed drastic effects on the community structure of the Tuggerah Lakes (New South Wales), causing a decline in both species number and diversity, specially in the mud sites compared to seagrass sampling stations. [10] studied the influence of the increased temperature of receiving waters affected the benthic populations of Tuticorin bay (SE coast of India), showing the increased of sea temperature a negative correlation with species abudance and diversity, as well as, macrofaunal biomass. [13] studied the soft-bottom macrofauna on the adjacent area of the Calvert Cliffs Nuclear Power Plant (Chesapeake Bay, Maryland, USA) observing increased abundances of the bivalve Mya arenaria and the nereidid polychaete Neanthes succinea at the discharge sites. On the contrary, no apparent effects caused by the thermal effluents were found in studied stations in terms of species abundances, diversity and abundance of the dominant species.

However, [2] worked in a long-term ecological survey of the adjacent sandy beach for several years and after the power station came into operation in Ayrshire (Scotland) observed small effects of thermal effluents in open seawaters so that the changes on the most abundant species were not attributable to these effluents. By contrast, some physiological effects were encountered in the bivalve Tellina tenuis and the sandburrowing amphipod Urothoe brevicornis. The growth rates of young T. tenuis appear to have increased after the opening of power station and U. brevicornis showed an earlier breeding season and more prolonged growth period in the affected beach, compared with a control population. [12] observed that benthic communities (macroand meiofauna) were seemed not to be influenced by the heated effluent. The latter 
studied assemblages did not exhibit significant differences between impact and control stations and the species composition of macrofauna did not provide any evidence of the presence of opportunistic and pollution-tolerant species.

In the water column, the increased seawater temperature was found to have no effect on planktonic copepods populations in the water receiving the discharges [16]. [11] observed a slightly increased of the seasonal phytoplankton biomass and prompted a less than 2-week earlier start to the spring bloom on the surrounding waters of a nuclear power station on the west coast of Finland. However, changes in nutrient supply driven by other factors had more influences on plankton community than the heated water.

In short, only limited areas or volumes of ambient seawater are affected by discharged heated water and the effects of the warmer water are considered to be modest and quite local.

The main aim of the present study was to assess spatio-temporal differences in macrofaunal community in the vicinity of a power station. 


\section{Material and Methods}

The study area belongs to the protected area "Sebadales del sur de Tenerife" (LIC ES7020116) and was comprised between Punta Sama to the north and Tanque del Vidrio to the south (SE coast of Tenerife, Canary Islands, NE Atlantic Ocean (Table 1; Fig. 1). This zone is protected leeward from the influence of the Canarian Current and the Northeast trade winds, allowing the development of extensive Cymodocea nodosa meadows from sheltered, intertidal pools up to 35 - $40 \mathrm{~m}$ deep [19]. However, all sampling stations were collected from sandy bare seabeds.

In this study, large-diameter core samples were collected to assess the differences in macrofaunal community structure between thermally polluted soft-bottoms and the nearby seabeds. The study area was affected by the cooling turbines of a power station that discharged $60^{\circ} \mathrm{C}$ to $70^{\circ} \mathrm{C}$ hot sea water all over the day at approximately speed of 1 $-2 \mathrm{~m} \mathrm{~s}^{-1}$.

Two campaings were carried out (summer (July 2003) and winter (January 2004) in this study. Five stations (12-20 m deep) were sampled during each campaign and three replicates were taken in each station. Sampling stations were characterized by the presence of sandy bare seabeds. Sediments collected in Station C are directly influenced by sea effluents from the power station. Stations A and B were located northwards, at $1.7 \mathrm{~km}$ (Sta. B) and $2.5 \mathrm{~km}$ (Sta. A) from the turbines. Stations D and E were situated southwards, at $0.8 \mathrm{~km}$ (Sta. D) and $1.2 \mathrm{~km}$ (Sta. E) from the effluent. (Fig. 1).

Sediment samples were collected by hand drilling into the sediment with a square metallic core $\left(0.1 \mathrm{~m}^{2}\right)$ to a depth of $20 \mathrm{~cm}$. Samples replicates were preserved in $10 \%$ seawater formaldehyde solution filtered through a $1 \mathrm{~mm}$ mesh sieve. In the laboratory, specimens were sorted and identified to species level whenever possible by means of a binocular microscope. Several individuals of small species were mounted in glycerine gel and examined using a LEICA DMLB microscope equipped with Nomarski interference contrast.

Biological descriptors of the macrofaunal community (Abundance, Species richness and Shannon's diversity) were calculated. The macrobenthic species responsible for the observed trends were identified by means of the SIMPER routine. The heterogeneity of the three replicates was calculated with the Index of Multivariate Dispersion (MDI). High values of MDI indicates that the dispersion of replicates are extremely high and 
the minimum value of 0 indicates the lack of dispersion among replicates. All former statistical analyses were carried out using the routines of the PRIMER 5.2. package (Plymouth Routines In Multivariate Ecological Analysis) [5, 6].

The ambient seawater on the bottom ranged from $17^{\circ} \mathrm{C}$ in winter and $20^{\circ} \mathrm{C}$ in summer in the area of the power station. The thermal effluent produces a mean increase of $4^{\circ} \mathrm{C}$ in the proximity of the discharge and its effect on the water column gradually decreases on increasing the distance from the effluent. At a distance of $20 \mathrm{~m}$ from the outfall, no differences were encountered $\left(<0.2{ }^{\circ} \mathrm{C}\right)$ in the bottom water and temperature differences are noticeable at very short distances (5-10 metres) due to the coastal area hydrodynamics that are responsible of a quick heat dispersion of the hot seawater plume. Punctual temperature measurements (by means of a CTD) were taken in the water column, $1 \mathrm{~m}$ far from the turbines $\left(20^{\circ} \mathrm{C}\right.$ in winter and $25^{\circ} \mathrm{C}$ in summer) and sea surface $\left(17^{\circ} \mathrm{C}\right.$ in winter and $20^{\circ} \mathrm{C}$ in summer). Therefore, seawater temperature cannot be used to assess the effects of the thermal effluents of the area nearby the power station.

Data set were re-arranged according to the following factors: 1) Seasonality (summer vs winter), 2), Stations (A-E). The respective differences in biological descriptors (abundance, species richness and diversity) were analyzed by means of one-way analyses of variance (ANOVA), after verifying the normality (using the KolmogorovSmirnov test) and homogeneity (Levene test) of variances [21]. When these assumptions were not met, a Kruskal-Wallis or a Mann-Whitney non-parametric test was used. These analyses were carried out using the SPSS 14.0 software.

\section{Results}

A total of 1.539 specimens were collected, belonging to 125 taxa, 101 determined to species level, 17 to genera, 2 and 5 to family and phylum level, respectively. Among the 19 taxonomical groups identified, the most diverse were polychaetes and amphipods with 73 and 14 species, respectively. The most abundant species were the interstitial polychaetes Pisione guanche, Saccocirrus papillocercus and the tanaid Apseudes talpa, with overall abundances of 118, 116 and 113 specimens, respectively. Other highly abundant species were the polychaete Questa cf. riseri and the amphipod Ampelisca brevicornis. 
Multivariate Dispersion Index (MDI) values ranged from 1.3 at station D (which had the lowest abundance and taxonomic richness) to 0.65 at station $\mathrm{C}$ (impact station, influenced by turbines), with the highest similarity among replicates. The MDI values of remaining stations were 0.71 (sta. E), 1.01 (sta. A) and 1.09 (sta. B) (Table 1).

\section{Summer vs winter}

There are not significant differences in macrofaunal community structure between summer and winter (ANOSIM R $=0.023, \mathrm{p}=0.063$ ). The abundance was similar with 15.24 and 15.44 ind. $50 \mathrm{~cm}^{-2}$, respectively and no significant differences were encountered (Mann-Whitney test $U=0.14 ; p=0.68$ ) (Fig. 2). Species richness tended to decrease in all sampling stations during winter, except on A and B (where there was a tendency to increase) and D (where it tends to remain constant) (Fig. 3). However, these differences were not statistically significant (Kruskal-Wallis test $Z=-0.340, p=0.734$ ). Shannon's diversity $\left(\mathrm{H}^{\prime}\right)$ a general trend to remain constant, and no significant differences were found (Mann-Whitney test $U=0.23 ; p=0.79$ ) (Fig. 4).

In July, the most representative species were the polychaetes Pisione guanche and Sacocirrus papillocercus, as well as, the amphipods Isaeidae and Ampelisca brevicornis. In January, the most abundant species was the tanaid Apseudes talpa. The slight differences in species composition between summer and winter could be explained by the differences in the abundances of the former species. No temporal (summer-winter) differences were found between macrofaunal abundances influenced by the seawater effluent and the remaining soft-bottom stations (Mann-Whitney test $U=$ $0.37 ; \mathrm{p}=0.81)$.

\section{Study Stations}

There were significant differences in macrofaunal community structure among the five stations (A-E) (ANOSIM 1-way, $\mathrm{R}=0.308, \mathrm{p}=0.001$ ). The macrofaunal abundances ranged from 8 ind. $50 \mathrm{~cm}^{-2}$ in station $\mathrm{D}$ to 23 ind. $50 \mathrm{~cm}^{-2}$ in station $\mathrm{A}$ and no significant differences were found (Fig. 2; Table 2). The differences in species number were significant (ANOVA 1-way, $\mathrm{F}=3.149, \mathrm{p}=0.018$ ), ranging from 23.1 in station A to 8.34 in station D (Fig. 3). In terms of Shannon's diversity $\left(\mathrm{H}^{\prime}\right)$, no significant differences were found (Kruskal-Wallis test $\chi^{2}=0.12 ; p=0.35$ ) (Fig.4). 
In station A, the polychaetes Pisione guanche, Saccocirrus papillocercus and Aricidea cf. assimilis explained the $68 \%$ of the similarity. In station B the polychaetes Parapionosyllis labronica, S. papillocercus and Scoloplos (Leodamas) sp. were responsible of the $64 \%$ of the similarity. In station $\mathrm{C}$ the amphipod Photis longicaudata, the polychaete Aponuphis bilineata, and the isaeid amphipod contributed to the $34 \%$ of the similarity. In station $\mathrm{D}$, the cumacean Iphinoe canariensis, the polychaete Prionospio steenstrupi and the amphipod Urothoe marina contributed to a $37 \%$ of the similarity. In station E, the amphipod Ampelisca brevicornis and the tanaid Apseudes talpa characterized this station by contributing to a $68 \%$ of the similarity. No significant differences were found between impacted and non-impacted stations.

\section{DISCUSSION}

Soft-bottom communities are often exposed to natural changes, almost interannual that can only be interpreted by means of long-term studies [20]. Although in the present study samples were collected only during two sampling periods (July and January) some conclusions can be made.

The macrofaunal community influenced by the sea effluent (Station C) was rather different compared with the remaining ones (control stations). During 1996 and 1997 some observations of soft-bottoms communities were made and confirmed the disappearance of finer sediments in the influence area of the heated water, and the presence of high amounts of silt-clay in the nearby seagrass meadows (J. Núñez, unpublished data). These phenomena, as well as, the presence of a particular community structure, dominated by polychaetes (Aponuphis bilineata and Chone spp.) and amphipods (Photis longicaudata), can be partially explained by the influence of the current intensity flowing from the turbines. However, no quantitative current measurements have been taken in this study, but a continuous current is noticeable from the seawater effluent. This water movement is responsible of the sedimentary characteristics of the impacted area with a dominance of medium and coarse sands, being scarce the fine sedimentary fractions (silt and clay and fine sands). In turn, the lowest MDI values observed in the impacted area of the sea effluent and these results 
confirmed the existence of a constant thermal perturbation causing homogenization of the affected soft-bottoms.

However, as mentioned above, the effects of temperature out of the effluent can be considered as negligible. Conversely the community showed a marked patchy distribution, as revealed by the high within-replicate variances of the univariate indices in the study area.

At a short-spatial scale, the Canarian macroinfauna seems to be characterized by local patches of high density ( $>30$ individuals) separated by a fairly variable inter-patch distance [9]. For this reason, it is not rare to get replicates that are deprived of infauna, together with others having over 40 individuals from the same location. [3] studied the temporal variability of polychaetes during a year basis in a Cymodocea nodosa meadow. The dominant polychaete species were syllids (Streptosyllis bidentata, Exogone parahomoseta mediterranea and Streptosyllis campoyi) and paranoids (Aricidea assimilis and Cirrophorus perdidoensis) and the polychaete structure clearly differs from the data obtained in the present study. The main reason is the use of different mesh sizes $(0.1 \mathrm{~mm}$ in [3] and $1 \mathrm{~mm}$ in this study), as well as, the differences of macrofaunal assemblages in both habitats (Cymodocea nodosa meadows vs sanby bare seabeds).

[15] observed a clear dominance of the tanaid Apseudes talpa in the sandy seabeds on the surroundings of a fish farm, being a frequent species of sandy bare bottoms in the Canarian archipelago, but some differences are found comparing macrofaunal structure from the two studies, like the absence of the polychaetes Aponuphis bilineata, Pisione guanche and Sacocirrus papillocercus that constituted an important macrofaunal fraction in the present study. [9] recorded the onuphid Aponuphis bilineata as one of the most abundant species, together with the serpulid Ditrupa arietina, that characterized extensive areas of sandy seabeds of the Canarian archipelago. [15] observed that spionids, onuphids and syllids were the only polychaete families recorded in all sampling sites.

In previous studies, the species composition of macrozoobenthos did not provide evidence of the presence of opportunistic or tolerant species and agreed with the sediment grain size structure [12], which is one of the major determinants of community responses in soft-bottoms [8]. However, several authors have observed changes in macrofauna community structure on the surroundings of power stations that have been shown to reduce the assemblages composition, to increase the abundance of 
opportunistic species and to alter population dynamics of the most abundant taxa. [14] reported high abundances of the capitellid Capitella capitata near the discharge of a power plant at Tampa Bay, Florida. [1] encountered species considered tolerant to thermal stress, such as the polychaete Cauleriella sp. and oligochaete Peloscolex sp. in the discharge waters of a power station on the river Medway Estuary, Kent.

These results confirmed that the different levels of heat dispersion in the seawater and the different thermal tolerance of the macrofaunal species may produced no, little or great measurable responses to the thermal disturbances. [18] encountered that much of the area that showed consistent thermal effects on benthic community structure, presented much higher temperature $\left(7-10^{\circ} \mathrm{C}\right.$ more than the ambient water) on the bottoms affected by the thermal discharge. However, [4] observed only $1-2^{\circ} \mathrm{C}$ more than the ambient water in bottoms affected by thermal pollution and no apparent effects were found in the macrofaunal community structure. In the present study, no appreciable temperature differences were detected mainly due to the hydrodynamics.

The particular community structure found in the impacted station may be related with large abundances of Aponuphis bilineata (which is not a filtrator or a depositfeeder that may respond to the increasing currents or to the accumulation of organic matter) in the sediments inside the turbine. This species is an active carnivorous polychaete [7] and has a fast response to the availability of preys (e.g. other infaunal organisms, including polychaetes). The concentration of potential preys in the influence area of the sea effluent (e.g. plankton entrainment losses) may represent an advantageous trait for the survival of this species, especially in an oligotrophic environment. The high punctual densities of this species may be the result of sampling over sediments harbouring clusters of individuals concentrated on sediment patches where preys were localized and abundant.

In short, slight differences were found in the macrobenthos community structure on the surroundings of turbines and no effects of temperature rise and mechanical damage in the turbines were detected. However, the thermal dispersion of the sea effluent and the thermal tolerance of the study species could play an important role in limiting the effects of the heated water. Therefore, further research is necessary to investigate the temporal variations of the assemblages on the impacted and control stations. 


\section{ACKNOWLEDGEMENTS}

This study was supported by a contract undertaken by the Electric Company UNELCO and SEMALL (Environmental Agency of the University of La Laguna), that provided logistic support and encouragenment, with special thanks to Prof. Venerando González (ULL). We are also grateful to the research staff of the Department of Animal Biology of the University of La Laguna that was involved in the present project, Prof. Alberto Brito, Gustavo González, Pedro Pascual, Mariano Pascual, Salvador Herrando and Alejandro Martínez.

\section{REFERENCES}

1. R.N. Bamber and J.F. Spencer, The benthos of a coastal power station thermal discharge canal. J. Mar. Biol. Ass. Uk. 64, 603-623 (1984).

2. P.R. Barnett, Some changes in intertidal sand communities due to thermal pollution. Proc Roy Soc London. Ser. Biol Sci. 177, 353-364 (1971).

3. M.C. Brito, J. Núñez, and D. Martín, Polychaetes associated to a Cymodocea nodosa seagrass meadow in the Canary Islands: assemblage structure, temporal variability and vertical distribution compared to other Mediterranean seagrass meadows. Mar. Biol. 146, 467-481 (2005).

4. R. Cironi, E. Ioannilli, and R. Vitali, Assessment on the effects of coastal power plants on marine biological resources in Italy. E and Fn Spon (eds.). In Coastal Ocean Space Utilization, eds. N. Della Croce, S. Connel and R. Abel, 313-329 pp, London. (1995)

5. K.R. Clarke, Non-parametric multivariate analyses of changes in community structure. Aust. J. Ecol. 18, 117-143 (1993).

6. K.R. Clarke, and R.M. Warwick, Changes in marine communities: an approach to statistical analysis and interpretation. Plymouth Marine Laboratory, UK, 144 pp (1994).

7. K. Fauchald, and R.A. Jumars, The diet of wonns: A study of polychaete feeding guide. Ocean. Mar. Biol. Ann. Rev. 17, 193-284 (1971).

8. J.S. Gray, The ecology of marine sediments. Cambridge University Press, 185 pp (1981).

9. S. Herrando-Pérez, G. San Martín, and J. Núñez, Polychaete patterns from an oceanic island in the Eastern Central Atlantic: La Gomera (Canary archipelago). Cah. Biol. Mar. 10. M. Kailasam, and S. Sivakami, Effect of thermal effluents discharge on benthic fauna of Tuticorin bay, south east coast of India. Ind. J. Mar. Sci. 33(2), 194-201 (2004). 
11. J. Keskitalo, Phytoplankton in the sea area off the Olkiluoto nuclear power station, west coast of Finlad. Ann. Bot. Fenn. 24, 281-299 (1987).

12. C. Lardicci, F. Rossi, and F. Maltagliati, Detection of thermal pollution: variability of benthic communities at two different spatial scales in an area influences by a coastal power station. Mar. Poll. Bull. 38(4), 296-303 (1999).

13. T-n. Loi, and B.J. Wilson, Macroinfaunal structure and effects of thermal discharges in a mesohaline habitat of Chesapeake Bay, near a Nuclear Power Plant. Mar. Biol. 55(1), 3-16 (1979).

14. S. Mahadevan, A study on the effects of power plant thermal discharges on benthic infaunal communities at Big Bend, Tampa Bay (Florida). Flor. Sci. 43, 7 (1980).

15. Ó. Monterroso, J. Núñez, and R. Riera, Macrofauna de fondos blandos en las concesiones de acuicultura de la Bahía de Igueste de San Andrés, Tenerife. Rev. Acad. Can. Cienc. 15, (3/4): 77-86 (2004).

16. M.M. Olson, Ecological studies in the middle reach of Chesapeake Bay. Lect. Not. Coast. Mar. Stud. 23, 38-81 (1987).

17. B.J. Powis, and K. Robinson, Benthic macrofaunal communities in the Tuggerah Lakes, New South Wales. Aust. J. Mar. Freshw. Res. 31(6), 803-815 (1980).

18. S. Qian, H. Chen, Z. Zhao, and Q. Zhang, A study of the effect of thermal pollution on seaweeds. J. Ocean Univ. Quing. 23, 22-34 (1993).

19. J. Reyes, Estudio de las praderas marinas de Cymodocea nodosa (Cymodoceaceae, Magnoliophyta) y su comunidad de epífitos en El Médano (Tenerife, Islas Canarias). Doctoral Thesis, University of La Laguna, Tenerife, Canary Islands (1993).

20. R. Sardá, D. Martín, S. Pinedo, A. Dueso, and M.J. Cardell, Seasonal dynamics of shallowwater benthic communities in the Western Mediterranean. In Nicolaidou, A. (ed.) The biology and ecology of shallow coastal waters. Olssen and Olssen, Fredensborg, 191-198 (1995).

21. R.R. Sokal, and B.A. Brauman, Significance tests for coefficient of variation and variability profiles. Syst. Zool. 29, 50-66 (1980).

22. I. Valiela, Global coastal change. Blackwell, USA, 368 pp (2006).

42(3), 275-287 (2001) 
Table 1. List of sampling stations and the Multivariate Dispersion Index (MDI).

\begin{tabular}{|c|c|c|c|c|}
\hline Stations & Locality & Depth & Sediment type & MDI \\
\hline A & Punta Sama & $15 \mathrm{~m}$ & Fine sand & 1.01 \\
\hline B & Punta Negra & $17 \mathrm{~m}$ & Fine sand & 1.09 \\
\hline $\mathrm{C}$ & $\begin{array}{c}\text { Power station } \\
\text { effluent }\end{array}$ & $15 \mathrm{~m}$ & Medium sand & 0.65 \\
\hline $\mathrm{D}$ & Punta Camello & $13 \mathrm{~m}$ & Fine sand & 1.30 \\
\hline $\mathrm{E}$ & Tanque del Vidrio & $13 \mathrm{~m}$ & Fine sand & 0.71 \\
\hline
\end{tabular}

Table 2. ANOVA 1-way $(F)$ of abundance and number of species $(\log x+1)$ transformed and non-parametric tests Kruskal-Wallis test $\left(\mathrm{X}^{2}\right)$ and the Mann-Whitney (U).* signifiacnt differences $(\mathrm{p}<0.05)$.

\begin{tabular}{lcc}
\hline & Seasonality & Stations \\
\hline \multirow{2}{*}{ Abundance } & $\mathrm{F}=0.047$. & $\mathrm{F}=0.601$. \\
& $\mathrm{p}=0.828$ & $\mathrm{p}=0.55$ \\
$\mathrm{~N}^{\mathrm{o}}$ species & $\mathrm{U}=-0.340$. & $\mathrm{F}=3.149$. \\
& $\mathrm{p}=0.734$ & $\mathrm{p}=\mathbf{0 . 0 1 8}^{*}$ \\
\hline
\end{tabular}


Figure 1. Location of sampling stations.

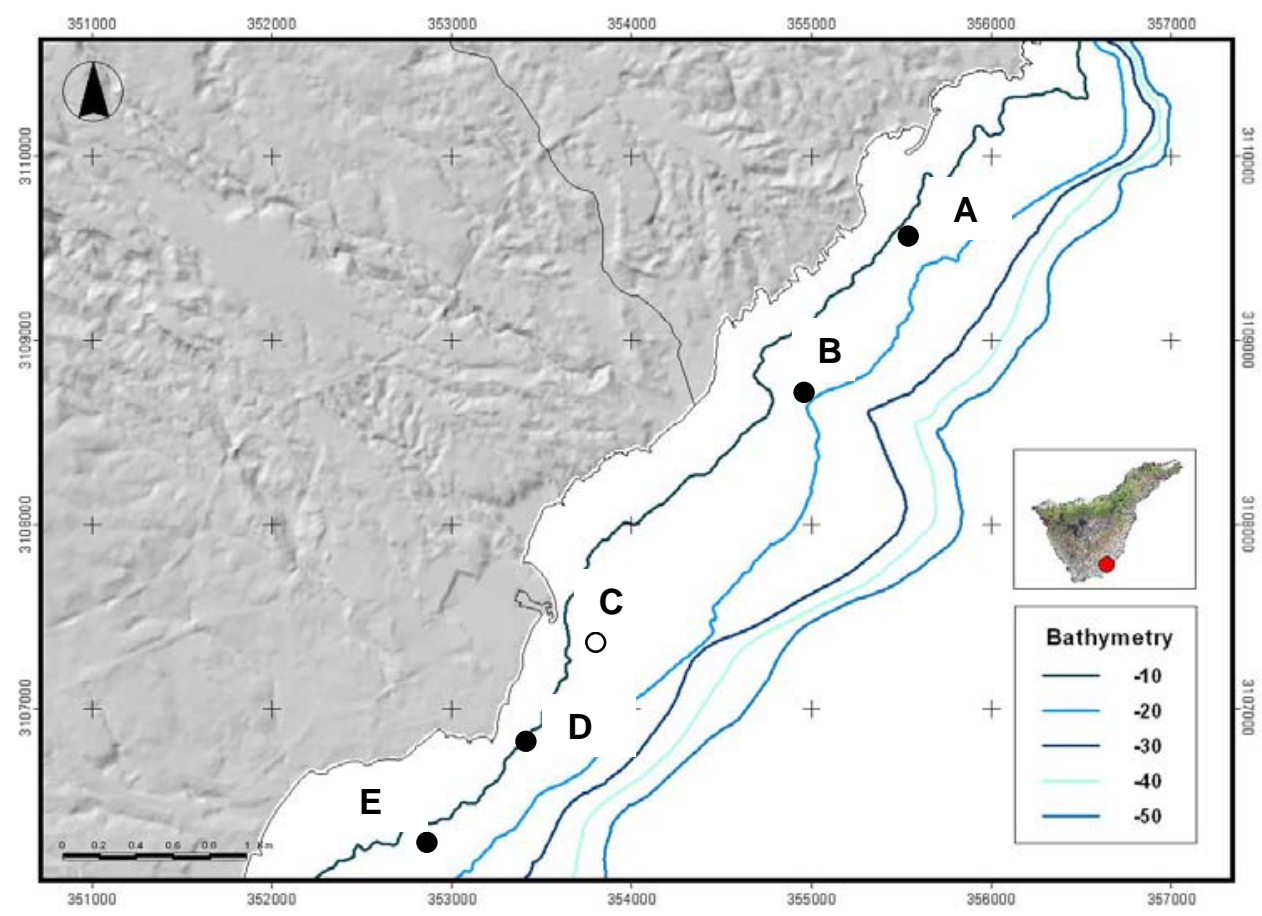

Figure 2. Macrofaunal abundances per sample. A. Seasonality $(\mathrm{S}=$ Summer; $\mathrm{W}=$ Winter). B Sampling stations (A-E).
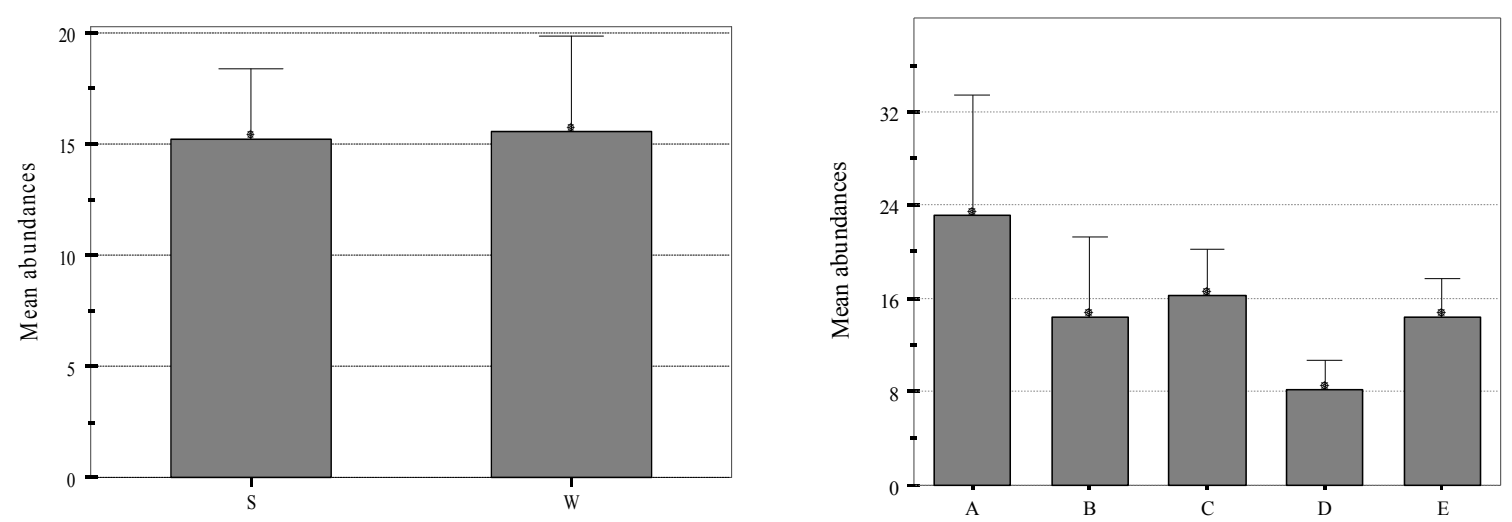
Figure 3. Species richness. A. Seasonality $(\mathrm{S}=$ Summer; $\mathrm{W}=$ Winter $)$. B Sampling stations (A-E).
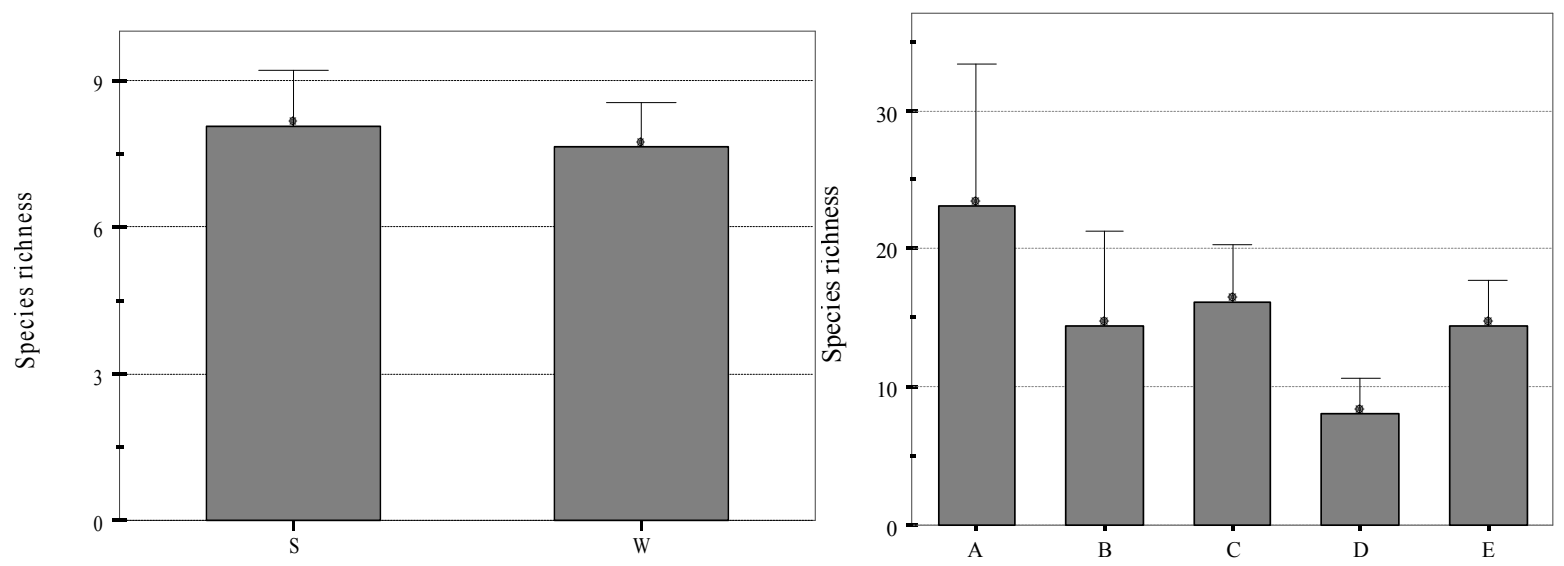

Figure 4. Shannon's diversity $\left(\mathrm{H}^{\prime}\right)$. A. Seasonality $(\mathrm{S}=$ Summer; $\mathrm{W}=$ Winter $)$. B Sampling stations (A-E).
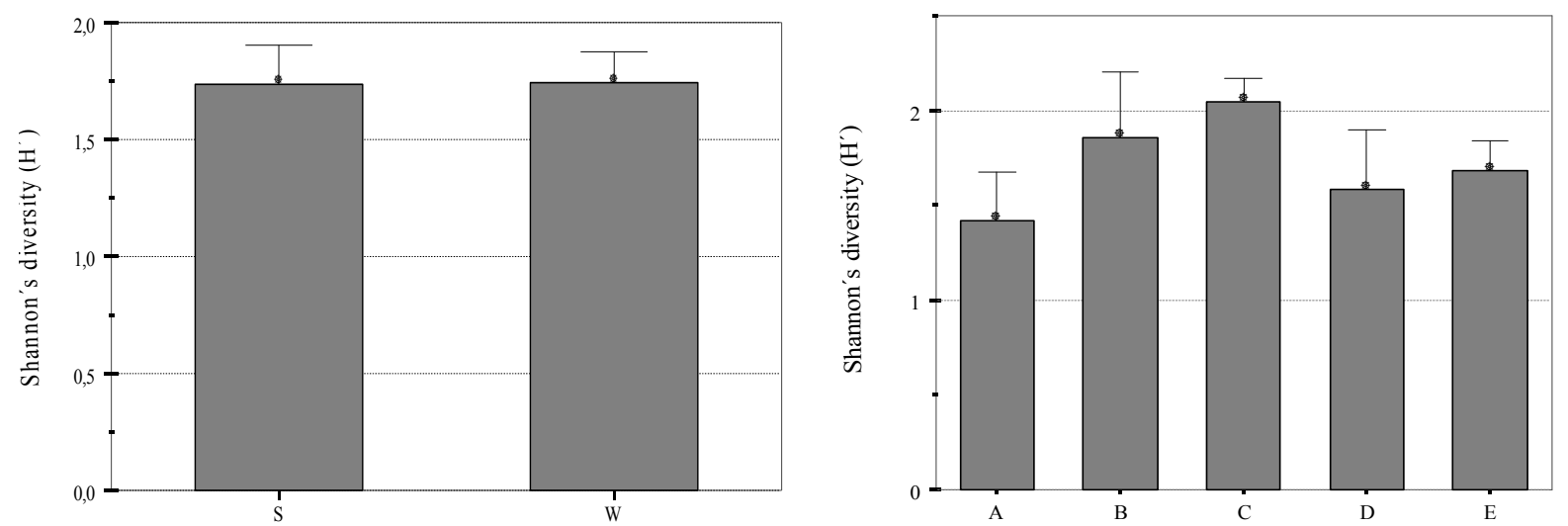